\title{
Bioclimatic approaches of modern residential architecture in Cyprus, 1952-1974
}

\author{
A. Michael and M. C. Phocas \\ Department of Architecture, Faculty of Engineering, \\ University of Cyprus \\ 75 Kallipoleos Avenue, P.O.Box 20537, Nicosia, 1678, Cyprus \\ Phone number:+ 357 22661130, Fax number: + 357 22667429, e-mail: aimilios@ucy.ac.cy, mcphocas@ucy.ac.cy
}

\begin{abstract}
In terms of energy efficiency, bioclimatic architecture aims at minimizing the energy consumption of the building and at achieving control of the microclimate of the indoor spaces. The bioclimatic dimension of residential architecture in Cyprus is examined on the basis of residential buildings, designed in the period 1952-1974 by the Cypriot architect Neoptolemos Michaelides. The selected projects are of a high national architectural significance, as they represent in a most distinct way a critical introduction of modern architecture in Cyprus. In architectural terms, the designs follow the functional disposition, without relying on symbolic or decorative parameters. Following an overview of modern architecture in Cyprus, in the specific period, the main climatic conditions of the region and the thermal comfort criteria are briefly presented. The analysis of five residential buildings, situated in the broader Nicosia district refers to the architectural design strategies, and the construction materials and systems, applied for achieving human comfort, as regards cooling and natural lighting. The study proves that a series of strategic design actions ensure thermal improvements of the buildings and lead to optimum levels of thermal comfort, enabling thus substantial energy profits.
\end{abstract}

\section{Key words}

Energy efficiency, bioclimatic design, residential architecture, thermal comfort, cooling.

\section{Introduction}

In terms of energy efficiency, bioclimatic architecture aims at minimizing the energy consumption of the building and at achieving control of the microclimate of the indoor spaces [1]-[3]. The bioclimatic approach aims at re-establishing the links of architecture with the principles of traditional building techniques [4]. This approach reduces or even eliminates the waste of energy in controlling the microclimate within a building. At the same time, it restores the contact of humans with nature, the idiosyncrasy of a place and the quality of life [2], [4], [5].
In Cyprus, bioclimatic architecture may apply to the climatic conditions over the entire year. In addition, the year-round sunlight and the high solar radiation make the need for exploiting solar energy even more mandating [3], [6]-[8]. The bioclimatic dimensions of residential architecture in Cyprus are examined on the basis of five selected residential buildings, designed in the period 1948-1992 by the architect Neoptolemos Michaelides [9], -[11] The selected projects are of high national architectural significance, as they represent in a most distinct way a critical introduction of modern architecture in Cyprus [10]. In architectural terms, the designs follow the functional disposition, without relying on symbolic or decorative parameters.

\section{Methodology}

The selection of the buildings was based on criteria that aim at a reduction of the high number of parameters, affecting the thermal comfort of the users. The sample includes residential buildings, all situated in the broader area of Nicosia (flat area with mean altitude of about 160 $\mathrm{m}$ ) for obtaining similar climatic conditions. It consists of five residential buildings with continuous function during the entire year. The buildings have one storey, two storey or split levels. As regards the year built, the buildings sample covers the entire time-span of the work of the architect and signify the multiple parameters of his architectural work. For the data acquisition, registration equipments of temperature and relative humidity of the type NOMAD, Data Logger were placed for 24 hours in the selected residences. The measurements were conducted from July 19th until August 26th of 2003. The registration equipment was placed in closed spaces of the ground floors, usually in the living room, at a height of $120 \mathrm{~cm}$ above the finished floor. The spaces have no technical climatic support. In two storey buildings the temperature was measured at 12:00 hrs at both, the ground floor and the first floor for obtaining possible differences over the height. 
Registration equipment was also placed in a reference building that was selected as suitable for comparison after registration of the temperatures of a broader possible reference buildings sample (Table I). The reference building is of similar materials, construction and size as the buildings selected for the analysis. It is a two storey building with open spaces. The roof and the external walls of the building are insulated with polystyrene. Data for the temperature and the relative humidity of the external environment was collected from the Meteorological Service of Cyprus, in particular from the Athalassa station (altitude: $162 \mathrm{~m}$, north geographic width: $35^{\circ} 09^{\prime}$, east geographic length: $33^{\circ} 24^{\prime}$ ).

Table I. - Results of data analysis of reference building

\begin{tabular}{lccccc}
\hline Temperature & 30.07 .03 & 31.07 .03 & 05.08 .03 & 11.08 .03 & 21.08 .03 \\
\hline $\max$ & 32.9 & 34.6 & 34.0 & 32.8 & 35.1 \\
$\min$ & 29.6 & 30.2 & 30.2 & 28.5 & 30.2 \\
average & 31.1 & 32.1 & 31.6 & 30.1 & 32.2 \\
fluctuation & 3.3 & 4.4 & 3.8 & 4.3 & 4.9 \\
\hline Humidity & & & & & \\
\hline $\max$ & 59.0 & 60.0 & 70.0 & 63.0 & 65.0 \\
$\min$ & 25.0 & 24.0 & 45.0 & 25.0 & 17.0 \\
average & 38.8 & 45.1 & 62.2 & 51.6 & 34.3 \\
fluctuation & 34.0 & 36.0 & 25.0 & 38.0 & 48.0 \\
\hline
\end{tabular}

\section{Buildings - Climatic Conditions Database}

The documentation of each residential building in the analysis refers to the applied design strategies for the improvement of microclimatic conditions [6], [7], [12]. In addition, the measurements of temperature and relative humidity for the time span of 24 hours are presented for each case, as well as the respective measurements for the reference building and the external environment.

\section{A. Theodotos Kanthos Res., design 1949, con.1952}

The residence building of Theodoros Kanthos is the first constructed design of the architect and the first building in the island within the frame-conditions of contemporary construction [9], [10], [11]. Apart from the residential spaces it contains a painting studio. The usage spaces are clearly divided into two levels. The common spaces are on the ground floor, the private ones on the 1st floor. The passage into the interior of the building contains three stages: The covered foreground, the glassed entrance space with the vertical circulation and the closed interior space. The differentiation of the building volumes over the height determines concrete visual connections and allows for a high level of natural lighting of the spaces. During the summer period the activities of the closed living room are transferred into the outer covered space that is defined by the structural grid, the water pond and the curved wall, encasing the painting studio. The data logger was placed on site at 19:00 hrs, 31st July 2003, for a time span of 24 hours. The results are presented in Figures 1, 2 and Table II.

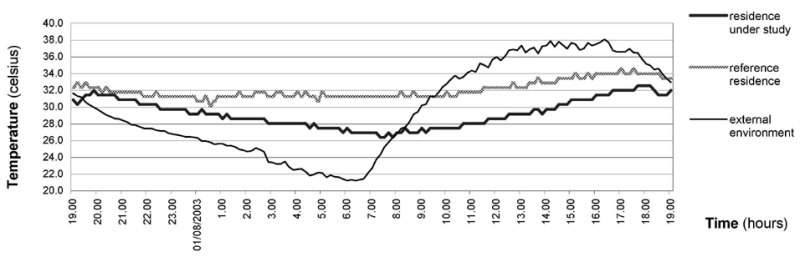

Fig 1. Temperature data of building in 3.A.

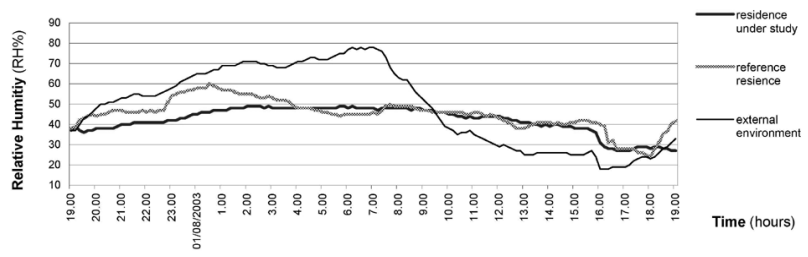

Fig 2. Relative humidity data of building in 3.A.

Table II. - Results of data analysis of building in 3.A.

\begin{tabular}{|c|c|c|c|}
\hline Temperature $\mathrm{C}^{\mathrm{O}}$ & Residence & Reference & External \\
\hline $\max$ & 32.6 & 34.6 & 38.1 \\
\hline $\min$ & 26.4 & 30.2 & 21.2 \\
\hline average & 29.3 & 32.1 & 29.8 \\
\hline fluctuation & 6.2 & 4.4 & 16.9 \\
\hline \multicolumn{4}{|l|}{ Humidity RH\% } \\
\hline $\max$ & 49.0 & 60.0 & 78.0 \\
\hline $\min$ & 27.0 & 24.0 & 18.0 \\
\hline average & 42.0 & 45.1 & 49.0 \\
\hline fluctuation & 22.0 & 36.0 & 60.0 \\
\hline \multicolumn{4}{|c|}{ Differences between reference and residence under study } \\
\hline & $\max$ & $\min$ & average \\
\hline Temperature $\mathrm{C}^{\mathrm{O}}$ & 2.0 & 3.8 & 2.8 \\
\hline Humidity RH\% & 11.0 & -3.0 & 3.1 \\
\hline \multicolumn{3}{|c|}{$\begin{array}{l}\text { Temperature Difference between ground and first } \\
\text { floor of the residence under study }\end{array}$} & $2.1 \mathrm{C}^{\mathrm{o}}$ \\
\hline
\end{tabular}

\section{B. Telemachos Kanthos Res., design 1959, con.1960}

The spaces of the building are divided in two levels, while the residence is situated on the ground floor, and the workshop of the painter within the upper volume, on the back-side of the plot. The large polygonal space of the living room comprises the main organisation element of the floor plan. The access to the workshop is achieved through an independent external staircase, so that privacy of the space is obtained. The inclined roof of the space and the large north glass facade that enables an uninterrupted view are most interesting elements of the composition. The semi-open air ground space underneath of the workshop is used as semi-open air living space in the summer. The vertical differentiation of the residence spaces and the workshop enables intensive visual connections towards all directions [10]. The data logger was placed on site at 12:00 hrs, 21st August 2003, for a time span of 24 hours. The results are presented in Figures 3, 4 and Table III. 


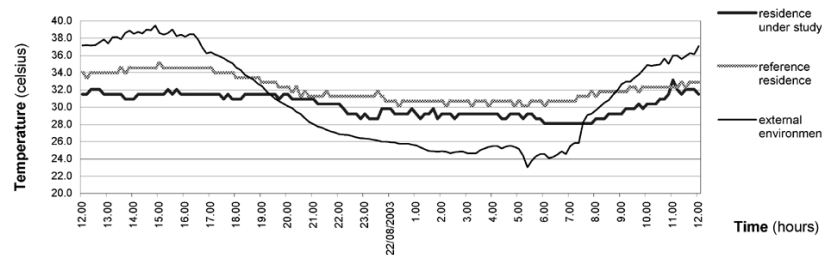

Fig 3. Temperature data of building in 3.B.

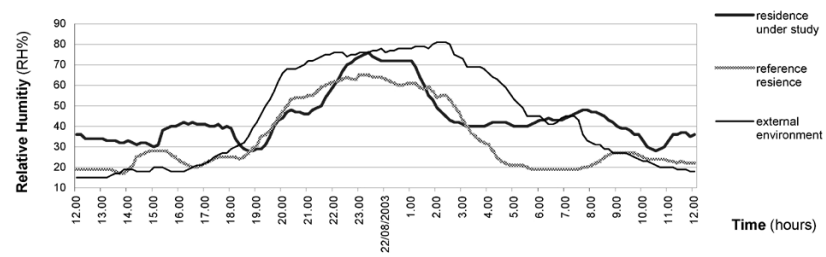

Fig 4. Relative humidity data of building in 3.B.

Table III. - Results of data analysis of building in 3.B.

\begin{tabular}{lccc}
\hline Temperature Co & Residence & Reference & External \\
\hline max & 33.2 & 35.1 & 39.5 \\
min & 28.1 & 30.2 & 23.0 \\
average & 30.2 & 32.2 & 30.8 \\
fluctuation & 5.1 & 4.9 & 16.5 \\
\hline Humidity RH\% & & & \\
\hline max & 76.0 & 65.0 & 81.0 \\
min & 28.0 & 17.0 & 15.0 \\
average & 44.1 & 34.3 & 45.0 \\
fluctuation & 48.0 & 48.0 & 66.0 \\
\hline
\end{tabular}

Differences between reference and residence under study

\begin{tabular}{lccc} 
& $\max$ & $\min$ & average \\
\hline Temperature Co & 1.9 & 2.1 & 2.0 \\
Humidity RH\% & -11.0 & -11.0 & -9.9 \\
\hline
\end{tabular}

Temperature Difference between ground and first floor of the residence under study

\section{Andreas Koumoulis Res., design 1964, con.1966}

The residence of Koumoulis Andreas is a two storey building, constructed on a highly inclined plot with the lower level at the back. The unified open spaces of the ground floor are articulated in their functions through altitude differences. The spaces with high energy consumption are situated on the south for maximum solar gains. The ground floor area contains a winter garden that is used as living room in the winter. The covered space at the southeast corner of the building is used as semi open space and as outdoor living room in the summer. All ground floor spaces are directly related with the open spaces [10]. The data logger was placed on site at 19:00 hrs, $11^{\text {th }}$ August 2003, for a time span of 24 hours. The results are presented in Figures 5, 6 and Table IV.

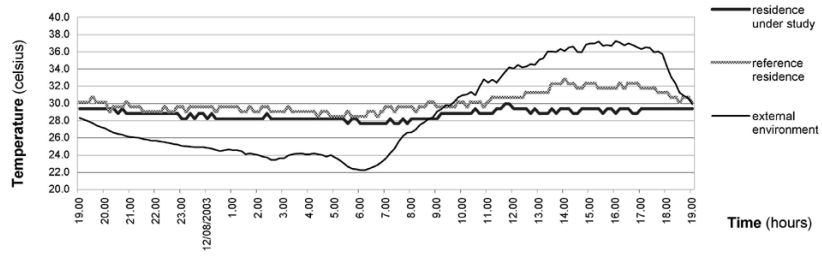

Fig 5. Temperature data of building in 3.C.

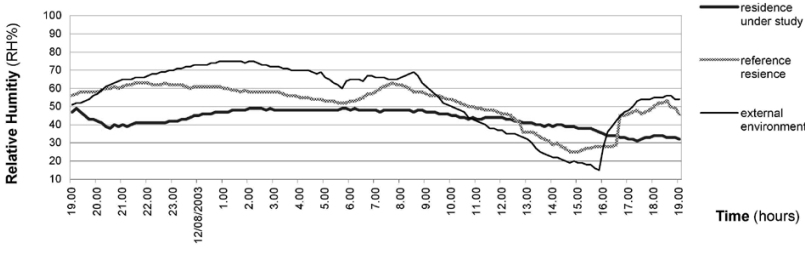

Fig 6. Relative humidity data of building in 3.C.

Table IV: Results of data analysis of building in 3.C.

\begin{tabular}{lccc}
\hline Temperature $\mathrm{C}^{\mathrm{o}}$ & Residence & Reference & External \\
\hline $\max$ & 29.9 & 32.8 & 37.3 \\
$\min$ & 27.7 & 28.5 & 22.3 \\
average & 28.7 & 30.1 & 28.9 \\
fluctuation & 2.3 & 4.3 & 15.0 \\
\hline Humidity RH\% & & & \\
\hline $\max$ & 49.0 & 63.0 & 75.0 \\
$\min$ & 31.0 & 25.0 & 15.0 \\
average & 43.0 & 51.6 & 55.5 \\
fluctuation & 18.0 & 38.0 & 60.0 \\
\hline
\end{tabular}

Differences between reference and residence under study

\begin{tabular}{lccc} 
& $\max$ & $\min$ & average \\
\hline Temperature $\mathrm{C}^{\mathrm{O}}$ & 2.9 & 0.8 & 1.4 \\
Humidity RH\% & 14.0 & -6.0 & 8.6 \\
\hline
\end{tabular}

Temperature Difference between ground and first $\quad 2.1 \mathrm{C}^{\circ}$ floor of the residence under study

\section{Panos Eliophotou Res., design 1965, con.1966}

The plot is situated at a height of about $2.5 \mathrm{~m}$ from the street level. The building develops at a horizontal level above the inclined ground section, while the parking places and the external staircase are at the level of the street. The entrance of the building is formed through the inclination of the dining room in the floor plan. The ground floor spaces are organised around an internal yard, forming thus a «U» shape with the south-east side open. This space comprises the main open space of the residence; in addition it divides the functional spaces of the building between social and private [10]. The data logger was placed on site at 14:00 hrs, $30^{\text {th }}$ July 2003 , for a time span of 24 hours. The results are presented in Figures 7, 8 and Table V.

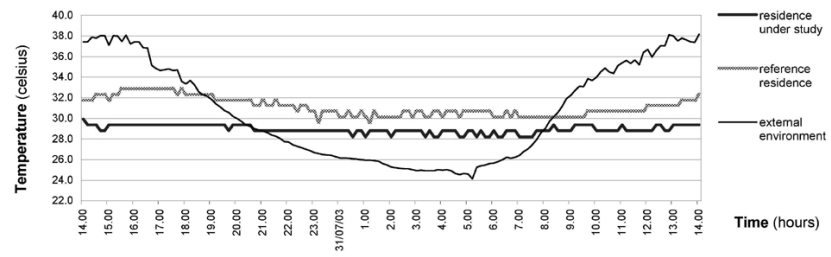

Fig 7. Temperature data of building in 3.D.

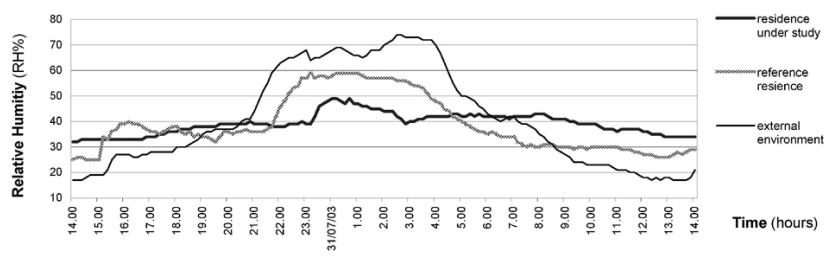

Fig 8. Relative humidity data of building in 3.D. 
Table V. - Results of data analysis of building in 3.D.

\begin{tabular}{|c|c|c|c|}
\hline Temperature $\mathrm{C}^{\mathrm{o}}$ & Residence & Reference & External \\
\hline $\max$ & 29.9 & 32.9 & 38.2 \\
\hline $\min$ & 28.2 & 29.6 & 24.2 \\
\hline average & 29.0 & 31.1 & 30.7 \\
\hline fluctuation & 1.7 & 3.3 & 14.0 \\
\hline \multicolumn{4}{|l|}{ Humidity RH\% } \\
\hline $\max$ & 49.0 & 59.0 & 74.0 \\
\hline $\min$ & 32.0 & 25.0 & 17.0 \\
\hline average & 39.2 & 38.8 & 41.1 \\
\hline fluctuation & 17.0 & 34.0 & 57.0 \\
\hline \multicolumn{4}{|c|}{ Differences between reference and residence under study } \\
\hline & $\max$ & $\min$ & average \\
\hline Temperature $\mathrm{C}^{\mathrm{O}}$ & 2.9 & 1.4 & 2.2 \\
\hline Humidity RH\% & 10.0 & -7.0 & -0.3 \\
\hline \multicolumn{3}{|c|}{$\begin{array}{l}\text { Temperature Difference between ground and first } \\
\text { floor of the residence under study }\end{array}$} & $2.1 \mathrm{C}^{\mathrm{o}}$ \\
\hline
\end{tabular}

\section{E. Nicos Georgiou Res., design 1967, con.1968}

The building houses, the residence and the doctoral practice of the owner. The open-air ground floor area with the garden leads to the entrance of the residence. The built-up volume on the ground level forms a «U» shape with the side towards the street open, while the first floor has an «L» shape. This disposition enables intensive visual connections. The two floors are connected through the atrium that comprises the central space of the floor plan. Through the placement of the atrium on the east side of the entrance, the spaces of the residence are divided effectively from the practice that functions independently. The two residence levels are characterized by a clear functional division, nevertheless the visual connection is achieved through the double height of the staircase space and large glass surfaces [10]. The data logger was placed on site at 13:00 hrs, $05^{\text {th }}$ August 2003 , for a time span of 24 hours. The results are presented in Figures 9, 10 and Table VI.

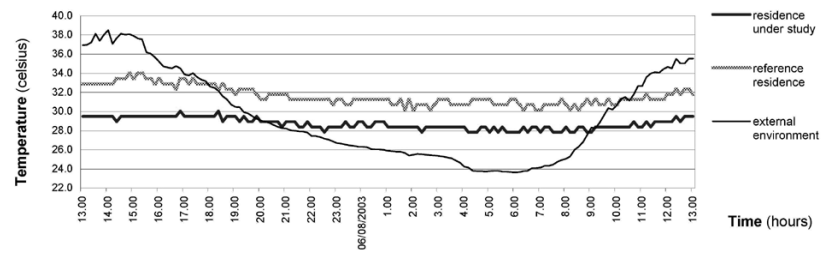

Fig 9. Temperature data of building in 3.E.

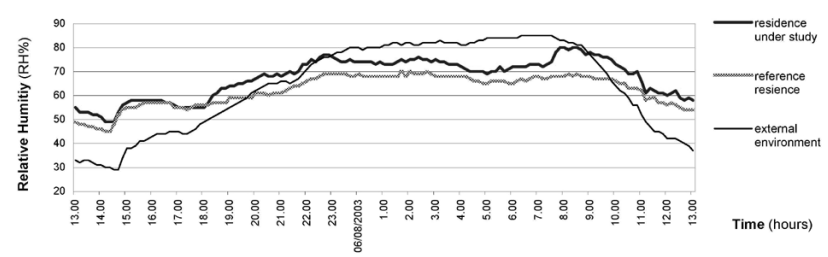

Fig 10. Relative humidity data of building in 3.E.

Table VI. - Results of data analysis of building in 3.E.

\begin{tabular}{lccc}
\hline Temperature $\mathrm{C}^{\mathrm{O}}$ & Residence & Reference & External \\
\hline $\max$ & 30.1 & 34.0 & 38.5 \\
$\min$ & 27.8 & 30.2 & 23.6 \\
average & 28.7 & 31.6 & 29.5 \\
fluctuation & 2.2 & 3.8 & 14.9 \\
\hline
\end{tabular}

\begin{tabular}{|c|c|c|c|}
\hline \multicolumn{4}{|l|}{ Humidity RH\% } \\
\hline $\max$ & 80.0 & 70.0 & 85.0 \\
\hline $\min$ & 49.0 & 45.0 & 29.0 \\
\hline average & 67.4 & 62.2 & 64.2 \\
\hline fluctuation & 31.0 & 25.0 & 56.0 \\
\hline \multicolumn{4}{|c|}{ Differences between reference and residence under study } \\
\hline & $\max$ & $\min$ & average \\
\hline Temperature $\mathrm{C}^{\mathrm{O}}$ & 3.9 & 2.3 & 2.9 \\
\hline Humidity RH\% & -10.0 & -4.0 & -5.3 \\
\hline \multicolumn{3}{|c|}{$\begin{array}{l}\text { Temperature Difference between ground and first } \\
\text { floor of the residence under study }\end{array}$} & $1.6 \mathrm{C}^{\mathrm{o}}$ \\
\hline
\end{tabular}

\section{Analysis}

\section{A. Bioclimatic Design}

Having in mind the rules and structural forms of modernism in architecture, Neoptolemos Michaelides attempted to materialise a modern architecture in Cyprus, strongly related to the climatic conditions and idiosyncrasies of the Cyprus landscape, as well as to specific spatial characteristics, such as the internal yard and the gradual passage towards the internal spaces [9]-[ 11]. In Neoptolemos Michaelides' work, the sun becomes a composed element, with the residences being opened or shielded against it; the wind determines the position and sizes of the openings, while vegetation and water become part of the buildings. Residences cease to be passive receptors of the weather conditions, but are composed so as to operate dynamically based on them [10]. A series of design strategies that appear from the beginning of the design process, ensure thermal improvements in the conditions of the buildings, approaching optimum levels of thermal comfort.

The definition of these parameters is attempted as follows, based on qualitative observations related to the summer and winter period (Fig. 11): The residence buildings have south or southeast orientation. The main spaces are situated towards the south, but when this is not possible, sunlight from the south is obtained through the use of skylights. The exterior walls have no openings towards the west and north, minimizing thus the thermal losses and preventing the cold winds during the winter season. Small-sized openings are suitably placed to ensure cooling during the summer months. The small openings increase the speed of wind in the interior of the buildings, improving the results of cooling.

Sun protection for the openings is achieved through projections, venetian blinds, pergolas and planting. Particular emphasis was given in avoiding an overheating of the spaces during the summer period.

Cooling plays perhaps the most important role for ensuring thermal comfort in the residences. It is achieved through openings on both, the external and internal walls that enable the flow of air throughout the residence. During the night it is achieved through openings on the roof and evaporation of water from reservoirs, waterworks and water pools. 
Suitable planting guarantees sun-protection and cooling of the interior of the residences. The presence of deciduous plants, trees and climbing bushes on the exterior walls supports the cooling and shading of the building, both horizontally and vertically. The fall of leaves during the winter months allows the entry of sunlight and consequently the heating of both, open-air and interior spaces. The presence of evergreen trees prevents, or directs the flow of air.

Atriums and internal patios contribute to the improvement of the climatic indoor conditions, due to the existence of vegetation and water in the core of the residences, while the non-compact configuration of the ground plan layouts ensures better ventilation of the interior spaces.

The thermal insulation of the building envelopes serves for the protection of the buildings from the outside weather conditions, increasing at the same time their thermal inactivity. Appropriate measures were taken for maximum natural lighting of the interior spaces. Large openings, atriums and rich vegetation ensure optical comfort, high level of lighting and pleasant views, criteria that affect the sentimental and psychological situation, as well as the thermal comfort of the occupants.
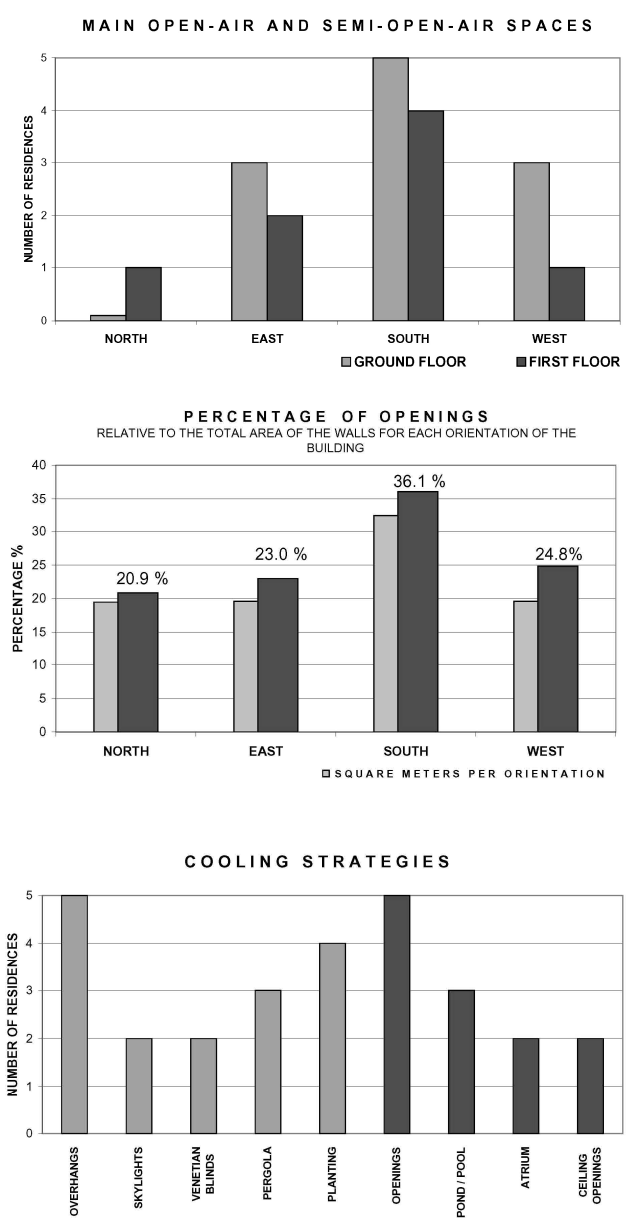

Fig 11. Bioclimatic design strategies, applied in the buildings sample

\section{B. Buildings Thermal Performance}

The mean maximum temperature of the buildings sample is $30.4{ }^{\circ} \mathrm{C}$, i.e. $3.0^{\circ} \mathrm{C}$ lower than the mean maximum temperature of the reference building. The respective temperature value of the external environment at the same time period is $37.9{ }^{\circ} \mathrm{C}$. The mean minimum temperature of the buildings is $27.8^{\circ} \mathrm{C}$, i.e. $3.2{ }^{\circ} \mathrm{C}$ lower than the mean minimum temperature of the reference building. The respective temperature value of the external environment is $23.4^{\circ} \mathrm{C}$, thus significantly lower than the temperatures in the interior spaces. The mean temperature fluctuation for the buildings is $2.7^{\circ} \mathrm{C}$ and for the reference building, $3.2{ }^{\circ} \mathrm{C}$. The similarity in these results is due to the fact that the buildings under review and the reference building are constructed with relatively heavy-weight materials of high heat inertia (> 400 $\mathrm{kg} / \mathrm{m}^{2}$ ). The mean temperature fluctuation of the external environment is $14.5^{\circ} \mathrm{C}$ (Fig. 12).

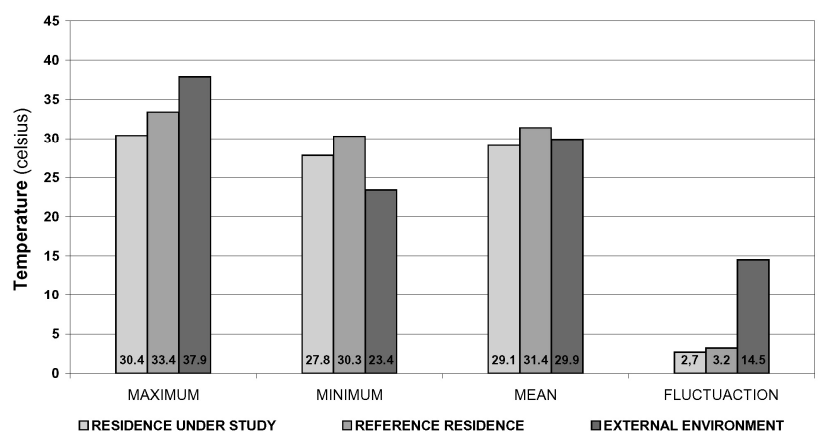

Fig 12. Comparison bars of mean temperatures

The buildings sample provided a mean maximum relative humidity of $57.6 \mathrm{RH} \%$, a mean minimum value of 37.6 $\mathrm{RH} \%$, i.e. a mean fluctuation value of $20.0 \mathrm{RH} \%$. The mean maximum relative humidity of the reference building is registered $4.4 \mathrm{RH} \%$ above the respective value of the buildings sample, and its mean minimum value is registered $5.6 \mathrm{RH} \%$ below the respective value of the buildings sample. These values give an increase of the mean fluctuation of $30.0 \mathrm{RH} \%$. For the same time period the external environment had a mean maximum relative humidity of $75.8 \mathrm{RH} \%$ and a mean minimum relative humidity of $22.2 \mathrm{RH} \%$. The respective fluctuation is $53.6 \mathrm{RH} \%$ (Fig. 13).

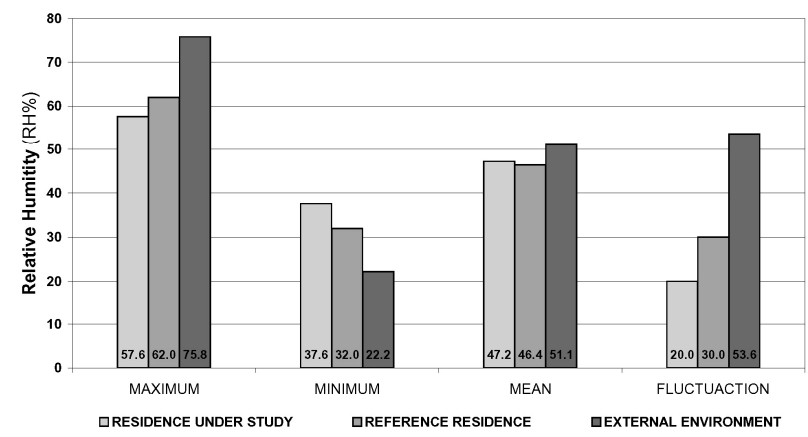

Fig 13. Comparison bars of mean relative humidity 
The diagrams of the mean temperature and the mean relative humidity for the entire time period provide information on the respective time-dependent fluctuations. In the case of temperatures, the fluctuation curves are similar. The buildings sample curve has significantly low values compared to the respective curve of the reference building, with $3.5^{\circ} \mathrm{C}$ at $14: 40 \mathrm{hrs}$ and 1.5 ${ }^{\circ} \mathrm{C}$ at 20:30 hrs. The corresponding curve to the external environment temperatures has high fluctuation, with a mean minimum value of $23.4^{\circ} \mathrm{C}$ at $05: 40 \mathrm{hrs}$ and a mean maximum value of $37.9{ }^{\circ} \mathrm{C}$ at $14: 40 \mathrm{hrs}$. Minimum temperatures in the buildings develop at 06:00 hrs and maximum ones, at 18:10 hrs. Although the external environment has a temperature fall from 14:40 hrs until 17:40 $\mathrm{hrs}$, at the same time span the buildings under review and the reference building show a temperature increase (Fig. 14). This is due to the thermal mass of the building envelope and the contribution of solar radiation in the interior spaces.

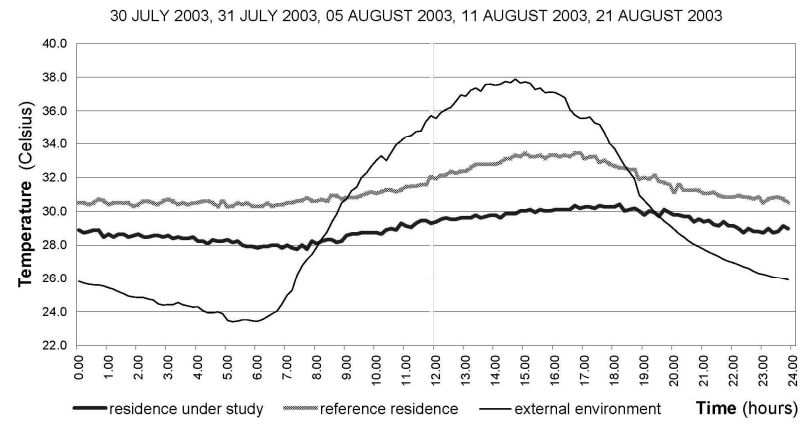

Fig 14. Mean temperature fluctuation curves

The graphic presentation of the mean relative humidity shows for the buildings sample a fluctuation value of $20.0 \mathrm{RH} \%$, for the reference building, $30.0 \mathrm{RH} \%$, and for the external environment, 53.6 RH\%. The registered mean values are almost constant, within a range from 47.2 $\mathrm{RH} \%$ to $51.1 \mathrm{RH} \%$. Maximum values develop during the evening hours (between 23:50 hrs and 00:50 hrs) and minimum values during the afternoon hours (Fig. 15). This proves the reciprocal relation between temperature and relative humidity.

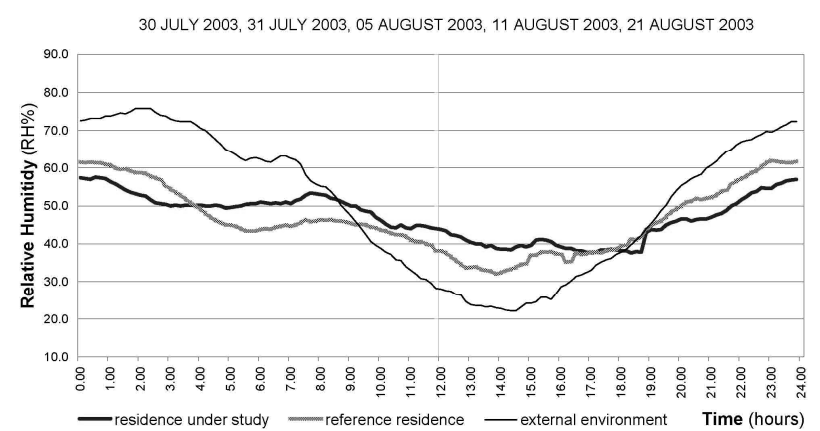

Figure 15. Mean relative humidity fluctuation curves

\section{Conclusions}

The architect Neoptolemos Michaelides aimed through his architectural work at environmentally and climatically sensitive designs, even though in the past years energy efficiency was not a primary case of concern. The bioclimatic principles, applied by the architect from the first stages of the design process, determine extensively the composition and the spatial configuration of the buildings [6], [7], [12]. This can be confirmed by the satisfactory results, obtained as regards the temperature and relative humidity of the five buildings reviewed for the summer period in this paper.

The collection of relevant data for the entire period of the year can provide a more rounded-up documentation of the thermal performance of the buildings. The research may be extended to include an evaluation of the level of natural lighting in the interior spaces and other parameters that contribute to the improvement of the energy efficiency of the buildings and the human comfort of the occupants.

\section{References}

[1] P.O. Fanger, Thermal comfort, McGraw-Hill, New York, (1973).

[2] B. Givoni, Man, climate and architecture, Applied Science Publishers, London, (1976).

[3] T.A. Markus and E.N. Morris, Buildings, climate and energy, Pitman, London, (1980).

[4] N. Michaelides, "Architecture for Earth", in Cypriot Popular Art, Pierides Foundation, Nicosia, in Greek, (1993).

[5] V. Olgyay, Design with Climate, Bioclimatic Approach to Architectural Regionalism, Princeton, New York, (1963).

[6] European Passive Solar Handbook, Preliminary Edition, Commission of the European Communities, Directorate General XII for Sciences, Research and Development, Brussels, (1986).

[7] B. Givoni, Passive and low energy cooling of buildings, Reinhold, New York, (1994).

[8] J. Goulding, et al, Energy in architecture, Malliaris Education, Thessalonica, in Greek, (1994).

[9] M. Economides, The relationship between modern and traditional in the work of the architect Neoptolemos Michaelides, Unpublished Research Project, Nicosia,(1992).

[10] A. Michael, The bioclimatic dimension in the work of Neoptolemos Michaelides, Unpublished Research Project, School of Architecture, National Technical University of Athens, Athens, in Greek, (2003).

[11] A. Michael, A. and A. Papanikolaou, The work of Neoptolemos Michaelides, Unpublished Research Project, School of Architecture, National Technical University of Athens, Athens, in Greek, (2002).

[12] Passive Solar Energy Efficient House Design, Architectural Association, School of Architecture, Energy Studies Programme, Department of Energy Solar Program, London, (1988). 